\title{
Experiências na utilização de um jogo mediado pelo uso da TDIC em ações educativas com adolescentes.
}

\author{
Marcela P. C. de A. Oliveira ${ }^{1}$, Rosana Juliet S. Monteiro ${ }^{2}$, Daniela T. Gontijo ${ }^{3}$ \\ ${ }^{1}$ Programa de Pós Graduação em Saúde da Criança e do Adolescente - Universidade \\ Federal de Pernambuco (UFPE) \\ Caixa Postal 50670-420 - Recife - PE - Brazil \\ ${ }^{2}$ Programa de Pós Graduação em Saúde da Criança e do Adolescente - Universidade \\ Federal de Pernambuco (UFPE) \\ ${ }^{3}$ Departamento de Terapia Ocupacional - Universidade Federal de Pernambuco (UFPE)

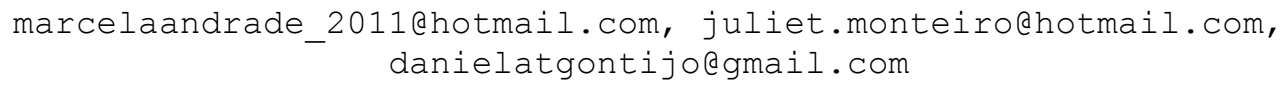

\begin{abstract}
The aim of this paper is to present the experiences of education and health professionals, participants of the research, on the use of a Serious Game mediated by a TDIC in educational actions with adolescents. From the experiences of the professionals, stands out the potential of the use of technologies in the educational actions with adolescents, and the intersectoral approach between health, education, and computing, mediated by the game.
\end{abstract}

Resumo. $O$ objetivo desse estudo é apresentar as experiências dos profissionais de educação e de saúde, participantes da pesquisa, sobre a utilização de um Serious Game mediado por uma TDIC nas ações educativas com adolescentes. A partir das experiências dos profissionais, destaca-se a potencialidade da utilização de tecnologias nas ações educativas com adolescentes, e da aproximação intersetorial entre a saúde, a educação, e a informática, mediada pelo jogo.

\section{Introdução}

Contemporaneamente a comunicação tem sido mediada pelas Tecnologias Digitais de Informação e Comunicação (TDIC) que são capazes de favorecer a criação de novas metodologias, oportunizar a realização de experiências que utilizam o suporte de recursos tecnológicos e ferramentas online para promover ensino e aprendizagem de conteúdos [SILVA; FILHO, 2016].

Especificamente com o público adolescente é cada vez mais frequente a presença das TDICs em atividades de lazer, no desenvolvimento de habilidades e em atividades didáticas, como por exemplo os jogos através do computador. Dessa forma, os jogos digitais podem ser um importante recurso de ensino-aprendizagem, pois, dentro de um contexto prazeroso, aprimoram a criatividade dos envolvidos, afloram potenciais que auxiliam na dinâmica do aprendizado e na construção crítica do conhecimento a partir da realidade [PERY; CARDOSO; NUNES, 2010; YONEKURA; SOARES, 2010].

Dessa forma, buscou-se apresentar, neste artigo, dados de uma pesquisa realizada para uma dissertação de mestrado que teve como proposta validar, com 
VI Congresso Brasileiro de Informática na Educação (CBIE 2017)

Anais dos Workshops do VI Congresso Brasileiro de Informática na Educação (WCBIE 2017)

profissionais de saúde e educação, um Serious Game, denominado DECIDIX, direcionado para promoção de saúde sexual e reprodutiva com adolescentes, a fim de garantir que a tecnologia seja utilizada por todos os profissionais que trabalhem na temática da educação sexual e cumpra a finalidade para o qual foi desenvolvido [OLIVEIRA, 2017].

Assim, o objetivo desse estudo é apresentar um recorte das experiências dos profissionais de educação e de saúde, participantes da pesquisa, no uso da TDIC nas suas ações educativas com adolescentes.

\section{Metodologia}

O presente estudo teve caráter descritivo e exploratório, com abordagem qualitativa [CRESWELL, 2014]. Teve como cenário escolas públicas da cidade do Recife, Olinda e Cabo de Santo Agostinho e Equipamentos Sociais da Comunidade do Recife. Fizeram parte do estudo 18 participantes, sendo 10 profissionais de saúde e 8 profissionais de educação.

Os participantes utilizaram o jogo em suas ações educativas com o público adolescente, sendo essas ações registradas no diário de campo pelos pesquisadores por meio da observação [CRESWELL, 2014]. Além disso, após a ação os participantes foram convidados a responder uma entrevista semiestruturada [CRESWELL, 2014].

Os dados qualitativos provenientes das entrevistas e do diário de campo foram agrupados, categorizadas, utilizando a técnica de análise de conteúdo temática em uma perspectiva qualitativa, de acordo com o referencial de Gomes [2010]. Foi garantido o sigilo dos participantes, codificando-os como Profissional de Saúde (PS) e Profissional de Educação (PE).

\section{Resultados e Discussão}

Durante as entrevistas os (as) profissionais de saúde e de educação refletiram sobre o uso de uma tecnologia em suas ações educativas afirmando que a utilização do DECIDIX na ação educativa foi motivadora e estimulou-os a continuarem inovando tecnologicamente nas ações futuras.

"para falar a verdade é tudo novidade.. ne? É tudo novidade. E a gente sabe que o tempo vai passando, e as coisas vão inovando.. agora é tecnologia mesmo.. tudo que a gene vai fazer é internet, É computador, É essas tecnologias mesmo.. e a gente como educador tem que ir evoluindo também. Se atualizando. E seguindo ne.. mais pra frente. Eu acho que foi ótimo. Muito bom. Isso é um começo.. (PS5)

Alguns profissionais de saúde e de educação apontam que a utilização desse recurso foi o diferencial na ação educativa, pois haviam utilizado poucas vezes o computador como mediador do debate. Mesmo aqueles profissionais que já haviam utilizado tal recurso, apontam que foi a primeira vez com essa temática e que é uma forma de enriquecer ainda mais as ações:

"E utilizando um game, um software, que assim, eu me identifico muito com a 
VI Congresso Brasileiro de Informática na Educação (CBIE 2017)

Anais dos Workshops do VI Congresso Brasileiro de Informática na Educação (WCBIE 2017)

utilização desse tipo de tecnologia na educação. Então eu achei bem produtivo esse casamento.. como já acho a muito tempo... mas assim, pela primeira vez utilizando aqui na escola e com um tema desse... que nunca havia utilizado software nenhum com esse tema..."(PE7)

Além disso, os (as) profissionais de saúde e de educação deste estudo também afirmaram que a utilização do recurso tecnológico favoreceu a aproximação educadoreducando, visto que esses profissionais inovaram trazendo outro tipo de material que, normalmente, não é utilizado nas ações educativas, mas que compõem o repertório cotidiano do e da adolescente. Ao agir dessa forma, o (a) educador (a) se aproxima do educando, de forma social e cultural, e a hipótese é de que o trabalho coletivo e colaborativo, entre ambos, possa ocorrer com maior fluidez [FEY, 2011].

"O que foi de diferente foi exatamente estar usando computador... diretamente com eles e o retroprojetor. Porque no geral eu trago outro tipo de material.. eu trago fantoches, cartolina, papel madeira.. .outros materiais. e a gente fala assim, mais de olhar no olho.. porque a gente teve esse momento de olhar no olho, mas a cada pausa que lia.. e ai, foi uma nova técnica, porque os jovens gostam muito de trabalho assim ne? Hoje eles estão da era da informática, avançam um pouco mais. Então, não rejeitando também as outras formas de trabalho. (...)eu acho que a gente tem que avançar né? Na realidade.” (PS4)

Apesar do advento da globalização, da ampliação e rapidez do acesso às novas tecnologias e de existirem políticas públicas voltadas para a integração das tecnologias no contexto escolar, observa-se que os avanços na direção de transformar e qualificar o processo de ensino-aprendizagem através da inserção dessas novas tecnologias ainda caminha a passos lentos [SOARES-LEITE E NASCIMENTO-RIBEIRO, 2012].

Embora ainda haja um desafio para o avanço das tecnologias, os profissionais de saúde e de educação já observam vantagens no uso dessas ferramentas. Esses profissionais de saúde e de educação compreendem a tecnologia como um recurso potencial e facilitador da construção do conhecimento de uma forma criativa, dinâmica, atrativa, interativa, transformadora e critica, além de ser considerado um recurso inovador [CARDOSO, 2011; FEY, 2011; MARIANO et. al., 2013; PERIM; GIANNELLA; STRUCHINER, 2014; YONEKURA; SOARES, 2010].

\section{Conclusões}

A partir das experiências dos profissionais, apresentadas nesse artigo, pode-se destacar a potencialidade da utilização de tecnologias nas ações educativas com adolescentes. Especificamente com o Serious Game avaliado, pode-se conjecturar que essa ferramenta provoca o (a) educador (a) a reflexão sobre sua prática educativa, seja o profissional de saúde em ações de educação em saúde, seja o professor, na construção do saber, e a (re) construir uma relação respeitosa e dialógica com os adolescentes.

\section{Referências}


VI Congresso Brasileiro de Informática na Educação (CBIE 2017)

Anais dos Workshops do VI Congresso Brasileiro de Informática na Educação (WCBIE 2017)

CARDOSO, T. M. A Aplicação das Tecnologias da Informação e Comunicação (TIC) no Ambiente Escolar. Revista Itec, vol. III, N 3, Dez. 2011.

CRESWELL, J. W. Investigação qualitativa e projeto de pesquisa: escolhendo entre cinco abordagens, $3^{\mathrm{a}}$ ed. Porto Alegre: Penso, 2014, p. 121-143.

FEY, A. F. A linguagem na interação professor-aluno na era Digital: considerações teóricas. Revista Tecnologias na Educação- ano 3- número 1- Julho 2011.

GOMES, R. Análise e interpretação de dados de pesquisa qualitativa in MINAYO, M. C. S.; DESLANDES, S. F.; GOMES, R. Pesquisa social teoria, método e criatividade. 33ª edição. Petrópolis, RJ: Vozes, 2013.

MARIANO, M. R.; PINHEIRO, A. K. B.; AQUINO, P. S.; XIMENES, L. B.; PAGLIUCA, L. M. F. Jogo educativo na promoção da saúde de adolescentes: revisão integrativa. Rev. Eletr. Enf., vol. 15, n. 1, p. 265-73, jan/mar, 2013.

OLIVEIRA, M. P. C. A. Utilização do DECIDIX para promoção de saúde sexual e reprodutiva na adolescência: estudo de validação. 2017. 175f. Dissertação (Mestrado) - Universidade Federal de Pernambuco, Recife, 2017.

PERIM, C. M.; GIANNELLA, T. R.; STRUCHINER, M. Análise do uso de um jogo para educação em saúde com adolescentes. Ensino, Saúde e Ambiente, v. 7, n. 1, Edição Especial, maio de 2014.

PERY, L.; CARDOSO, S.; NUNES, W. Jogos Educativos Digitais: Ludicidade e Interatividade no Ensino nas Séries Iniciais. En J. Sánchez (Ed.): Congresso Iberoamericano de Informática Educativa, v. 1, Santiago de Chile, 107-113, 2010.

SILVA, M. A.; FILHO, J. A. C. Trabalho colaborativo com suporte digital: uma experiência de formação docente. In: V Congresso Brasileiro de Informática na Educação (CBIE 2016) - Anais do XXII Workshop de Informática na Escola (WIE 2016).

SOARES-LEITE, W. S.; NASCIMENTO-RIBEIRO, C. A. do. A inclusão das TICs na educação brasileira: problemas e desafios. magis, Revista Internacional de Investigación en Educación, 5 (10), 173-187, 2012.

YONEKURA, T.; SOARES, C. B. O jogo educativo como estratégia de sensibilização para coleta de dados com adolescentes. Rev. Latino-Am. Enfermagem, v. 18, n. 5, p.07 telas, Set-out. 2010. 